\title{
Long-axis fractional shortening and mitral annulus motion in dogs
}

\author{
Fração de encurtamento longitudinal e movimento anular mitral \\ em cães
}

\author{
Marlos Gonçalves Sousa ${ }^{1 *}$; Fabio Nelson Gava ${ }^{2}$; Jorge Cardoso da Silva Filho \\ Sheila Nogueira Saraiva da Silva ${ }^{3}$; Rafael Rodrigues Camacho ${ }^{3}$; Roberta Carareto ${ }^{1}$; \\ Marcela Wolf ${ }^{4}$; Aparecido Antonio Camacho ${ }^{5}$
}

\begin{abstract}
Ventricular systolic dynamics involves the contraction of transverse and longitudinal myocardial fibers. Unfortunately, only the activity of the transverse myocardial fibers is foreseen by the standard systolic echocardiographic parameters. Although strain and strain rate have been used to assess the radial, circumferential and longitudinal planes of cardiac contraction, such analysis requires advanced equipment which is not always available in veterinary medicine. On the contrary, some unusual parameters may be recorded via standard methodology, allowing for the specific evaluation of left ventricular longitudinal contractility. In this study, the longitudinal contractile activity was evaluated using the long-axis fractional shortening and the mitral annulus motion, which were compared with several standard echocardiographic parameters in 14 beagles, including seven with asymptomatic mitral valve disease. The long-axis fractional shortening was positively correlated with both the mitral annulus motion and the end-diastolic left-ventricular diameter. Also, a significant correlation was found to exist between the mitral annulus motion and the left-ventricular end-diastolic diameter, which is likely supportive of its preload dependency. Even though no difference was documented in either mitral annulus motion or long-axis fractional shortening between healthy dogs and dogs with mitral valve disease, the latter only included animals with minimal cardiac remodeling, with no overt compromise of systolic function. Since it is possible to obtain these two parameters with any echocardiographic equipment, their inclusion in the routine exam would probably add information regarding the activity of the longitudinal myocardial fibers, whose functional deterioration supposedly occurs prior to the impairment of transverse fibers.
\end{abstract}

Key words: Left ventricle. Systolic function. Echocardiogram. Longitudinal contractility. Endocardiosis.

\section{Resumo}

A dinâmica ventricular sistólica envolve a contração de fibras miocárdicas transversais e longitudinais e, infelizmente, os parâmetros ecocardiográficos de função sistólica utilizados rotineiramente estão focados apenas na atividade das fibras transversais. Embora a deformação e a taxa de deformação miocárdicas venham sendo utilizadas para avaliar a contração cardíaca nos planos radial, circunferencial

\footnotetext{
${ }^{1}$ Profs., Departamento de Medicina Veterinária, Universidade Federal do Paraná, UFPR, Curitiba, PR, Brasil. E-mail: marlos98@ ufpr.br; robertacarareto@hotmail.com

2 Pesquisador, Universidade Estadual Paulista, UNESP, Jaboticabal, SP, Brasil. E-mail: gavacardiovet@gmail.com

3 Discentes de Doutorado, Universidade Estadual Paulista, UNESP, Jaboticabal, SP, Brasil. E-mail: filhojcs@hotmail.com; nogueirasss@yahoo.com.br; rafaelcamachomedvet@hotmail.com

${ }^{4}$ Discente de Mestrado, UFPR, Curitiba, PR, Brasil. E-mail: marcelawvet@gmail.com

${ }^{5}$ Prof., Departamento de Clínica e Cirurgia Veterinária, UNESP, Jaboticabal, SP, Brasil. E-mail: camacho@fcav.unesp.br

* Author for correspondence
} 
e longitudinal, tal análise requer equipamentos avançados que nem sempre estão disponíveis na Medicina Veterinária. Por outro lado, alguns parâmetros não usuais podem ser quantificados valendose de metodologia convencional, permitindo avaliar especificamente a função contrátil longitudinal do ventrículo esquerdo. Neste estudo, a atividade contrátil longitudinal foi avaliada por meio da fração de encurtamento longitudinal e do movimento anular mitral, os quais foram comparados com diversas variáveis ecocardiográficas convencionais em 14 Beagles, sendo sete deles portadores de doença valvar mitral assintomática. A fração de encurtamento longitudinal apresentou correlação positiva com o movimento anular mitral e com o diâmetro do ventrículo esquerdo em diástole. Também houve correlação significativa entre o movimento anular mitral e o diâmetro ventricular esquerdo em diástole, o que pode sugerir sua dependência da pré-carga. Embora não tenham sido observadas diferenças no movimento anular mitral e na fração de encurtamento longitudinal entre cães saudáveis e valvulopatas, há que se enfatizar que os animais com doença mitral apresentavam apenas mínimo remodelamento cardíaco, sem quaisquer indícios de comprometimento da função sistólica. Destarte, dada a possibilidade de mensurar ambos os parâmetros em qualquer equipamento de ecocardiografia, sua incorporação ao exame ecocardiográfico de rotina provavelmente agregaria informações sobre a atividade das fibras miocárdicas longitudinais, cuja deterioração funcional supostamente ocorre de modo precoce comparativamente às fibras transversais.

Palavras-chave: Função sistólica. Ventrículo esquerdo. Ecocardiograma. Contratilidade longitudinal. Endocardiose.

\section{Introduction}

Several echocardiographic parameters are focused on left ventricular systolic function, which has been widely studied in both animals and people. Measures such as the circumferential and area fractional shortenings are commonly used, but they are poorly correlated with other invasive techniques (ATKINS et al., 1992). It is worth mentioning, however, that ventricular systolic dynamics involves the contraction of two different types of guidance myocardial fibers: transverse, which are responsible for the transverse/radial myocardial contraction, and longitudinal, which contract in a longitudinal fashion. This arrangement of fibers results in three orthogonal planes, namely longitudinal, transverse and circumferential, whose interaction allows for the heart to rotate and twist. The conventional fractional shortening is targeted at the transverse/ circumferential fibers, while the long-axis fractional shortening evaluates the longitudinal contraction (AURIGEMMA, 1995; PAI et al., 1991).

Although the circumferential myocardial fibers have been considered to be mainly responsible for ventricular contraction, the longitudinal fibers are known to play an important role in systolic activity, especially in people with cardiac diseases, as well as in animals with altered ventricular geometry and contractility (AURIGEMMA, 1995). Jones et al. (1990) reported that all myocardial layers are involved in cardiac contraction and, interestingly, with systolic dysfunction, the longitudinal fibers might be the first to be impaired even while the circumferential fibers are still normal.

Because the apical descent of the mitral annulus plays an active role in the global left ventricular systolic shortening, the mitral annulus motion (MAM) has the potential to contribute useful information that allows a better assessment of cardiac function (EMILSSON et al., 2001; SCHOBER; FUENTES, 2001). While the mitral ring moves toward the heart apex during cardiac systole, during diastole it pushes backward to the left atrium (JONES et al., 1990). These displacements are recorded by M-mode echocardiography and the difference in the wave amplitude is used for calculation of MAM. The highest wave corresponds to end diastole, while the lowest one is obtained at end systole (SCHOBER; FUENTES, 2001). While MAM was shown to be a reliable and straightforward method to identify 
systolic impairment non-invasively (ALAM, 1991), it may not be useful for recognizing regional systolic dysfunction (HU et al., 2013).

Also, because the cardiac apex does not exhibit significant movement along the cardiac cycle, MAM is directly related to the longitudinal systolic shortening of the left ventricle, since alterations in the long axis are likely attributable to the displacement of the mitral ring toward the apex (JONES et al., 1990). In some studies, however, it has been compared with either the ejection fraction or shortening fraction, which are both dependent on the radial displacement of the myocardium. On the other hand, Emilsson et al. (2006) recommended its comparison with the long-axis fractional shortening (LAFS), which is obtained by dividing MAM by the left-ventricular end-diastolic length.

In this study, we hypothesized that the MAM would correlate with the long-axis left-ventricular shortening fraction instead of correlating with the radial shortening fraction and B-mode-derived ejection fraction. Therefore, this study was undertaken to investigate how the left-ventricular long-axis fractional shortening and the MAM perform in a group of healthy dogs and dogs with asymptomatic mitral valve disease.

\section{Material and Methods}

\section{Animals}

Fourteen mature beagle dogs (11.7 \pm 1.4 $\mathrm{kg}$; eight males) belonging to the university's experimental kennel were recruited for a prospective cross-sectional observational study in which the MAM and the left-ventricular long-axis fractional shortening were investigated. Seven of the dogs were completely normal, while the remainder had asymptomatic mitral valve disease and minimal cardiac remodeling (ACVIM class B2). None of the animals were under treatment. The study was entirely conducted in accordance with guidelines outlined in the National Institutes of Health Guide for the Care and Use of Laboratory Animals and was previously approved by the institutional committee for animal research under protocol number 6022/13.

\section{Echocardiography}

Every dog included in this study underwent a goal-directed ECG-gated echocardiogram using a $5 \mathrm{MHz}$ phased-array transducer, which included the following parameters: left ventricle internal diameter at end-systole $\left(\mathrm{LV}_{\mathrm{s}}\right)$, left ventricle internal diameter at end-diastole $\left(\mathrm{LV}_{\mathrm{d}}\right)$, fractional shortening $\left(\mathrm{FS}_{\%}\right)$, ejection fraction $\left(\mathrm{EF}_{\%}\right)$, left atrium-to-aorta ratio (LA/Ao), MAM, and left-ventricular longaxis fractional shortening (LAFS). Heart rate (HR) during the exam was also recorded. No sedatives or anesthetics were used, and the animals exhibited a normal respiratory rate throughout the exam.

Apical four-chamber images obtained from the left parasternal window were used for calculation of the MAM, which required the M-mode line to be directed through both the septal and lateral part of the mitral annulus. Oblique or angled views were avoided. For each site, the displacement of the mitral ring toward the cardiac apex during systole was recorded and measured. The leading edge technique was used and MAM was considered as the average of the two sites (Figure 1). This result was indexed to body surface area. To calculate the LAFS, we used apical four-chamber images and measured the left-ventricular end-diastolic length $\left(\mathrm{LVL}_{\mathrm{d}}\right)$ from the septal site of the mitral annulus to the epicardial apex. The LAFS was then calculated by dividing MAM by $\mathrm{LVL}_{\mathrm{d}}$. The standard radial $\mathrm{FS}_{\%}$ was calculated as $\left[\left(\mathrm{LV}_{\mathrm{d}}-\mathrm{LV}_{\mathrm{s}}\right) / \mathrm{LV}_{\mathrm{d}}\right] \cdot 100$, the $\mathrm{EF}_{\%}$ was calculated by the modified uniplanar Simpson's rule from apical four-chamber views, and finally, LA/Ao was calculated from transverse views of the heart base obtained from the right parasternal window. 
Figure 1. Echocardiographic images illustrating the steps needed to record the mitral annulus motion. (A) Apical four-chamber image with the M-mode line directed through the septal part of the mitral annulus. The asterisk indicates the lateral part of the mitral annulus. (B) M-mode image showing how the mitral annulus motion is calculated. The arrow represents the mitral annulus motion, which indicates the maximal displacement (dotted line) of the mitral ring toward the cardiac apex during systole.
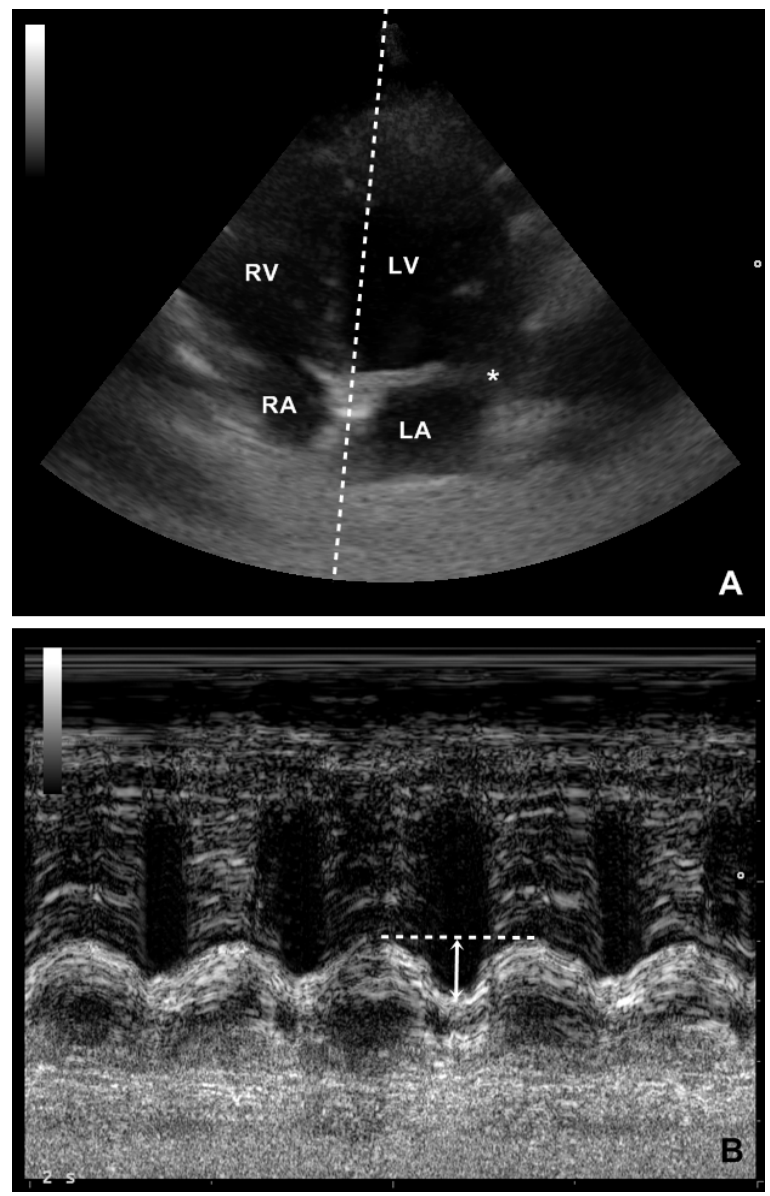

\section{Statistical analyses}

Descriptive statistics were used to describe population characteristics. After the data underwent the Shapiro-Wilk test, an unpaired $\mathrm{T}$ test was used to look for differences in LAFS and MAM in accordance with gender and competency of the mitral valve. Also, Pearson's coefficients were calculated to investigate correlations between MAM and LAFS, as well as between these two parameters and several standard echocardiographic data. The same test was used as an estimate of agreement in the reproducibility study. All analyses were performed using the software Prism ${ }^{\circledR}$ v.5.04 (Graphpad Software, San Diego CA, USA), with significance set at $\mathrm{P}<0.05$.

\section{Results}

The exam was performed without complication in every animal included in this investigation and both MAM $_{\text {index }}$ and LAFS were easily obtainable. Since we used a goal-directed approach, we could not estimate how much time the inclusion of these two parameters would add to the standard echocardiographic examination. Nonetheless, since the procedures involved with the acquisition of these unusual parameters are commonplace, prolongation of time needed to evaluate cardiac morphology and function is not likely to occur when the exam is completed by an experienced sonographer.

No significant differences were documented for $\mathrm{MAM}_{\text {index }}$ and LAFS calculated for either male $(n=8)$ or female $(n=6)$ dogs, as well as for those with either competent mitral valves $(n=7)$ or mitral insufficiency $(\mathrm{n}=7)$ (Figure 2). Table 1 gives the results of mean, standard deviation, $25 \%$ and $75 \%$ percentiles, and $95 \%$ confidence intervals for LAFS and the indexed MAM. 
Figure 2. Means and individual values of the long-axis fractional shortening (LAFS) and the mitral annulus motion indexed to body surface area $\left(\mathrm{MAM}_{\text {index }}\right)$ analyzed in accordance with gender $(\mathrm{A}, \mathrm{C})$ and either the presence or absence of mitral insufficiency $(\mathrm{B}, \mathrm{D})$.
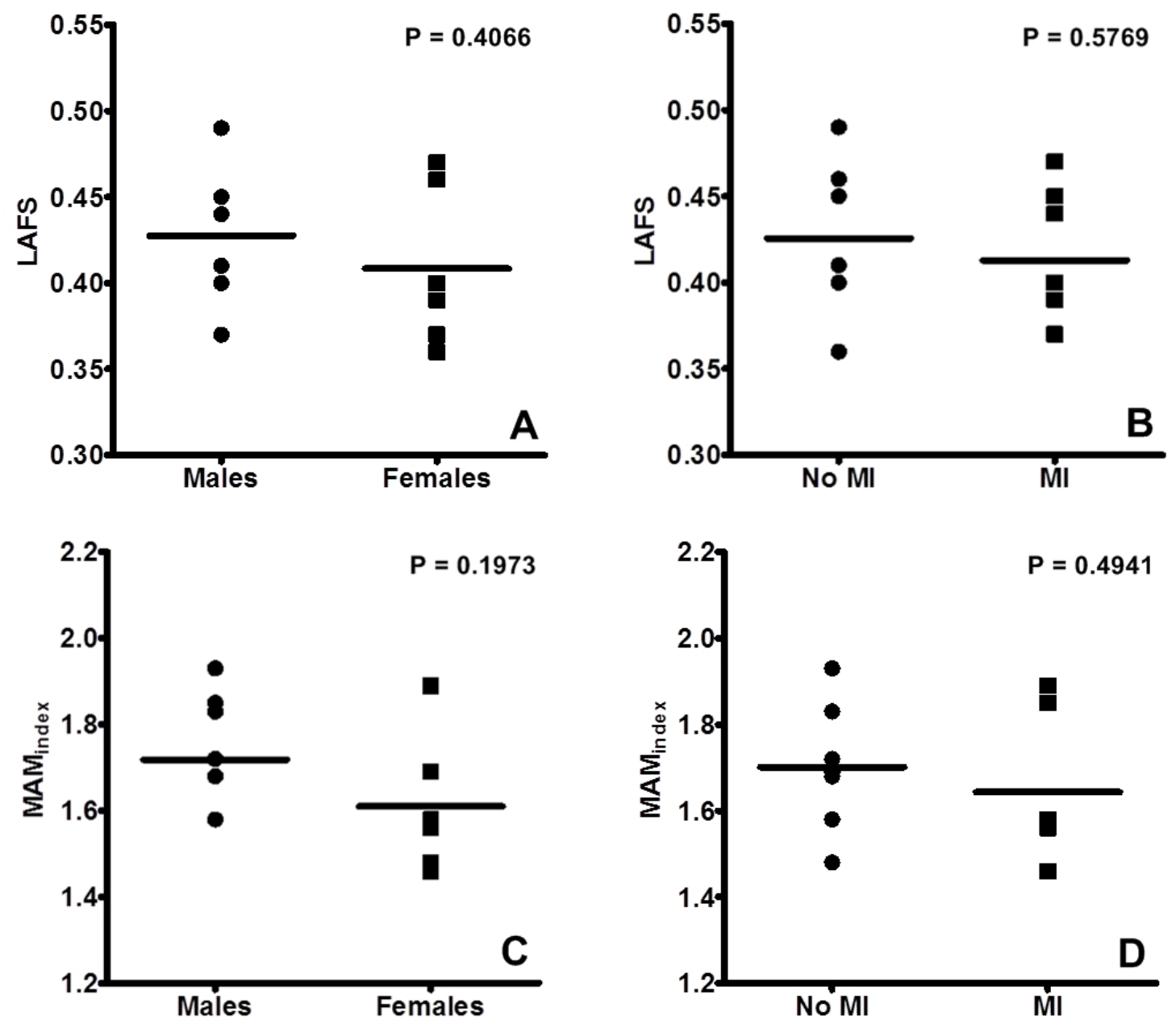

Table 1. Mitral annulus motion and long-axis fractional shortening in dogs.

\begin{tabular}{|c|c|c|c|c|}
\hline Parameter & Mean & SD & $25 \%, 75 \%$ percentiles & $95 \% \mathrm{CI}$ \\
\hline $\operatorname{MAM}_{\text {index }}\left(\mathrm{cm} \mathrm{m}^{-2}\right)$ & 1.6720 & 0.1523 & $1.5750,1.8350$ & $1.5840,1.7600$ \\
\hline LAFS (\%) & 0.4193 & 0.0408 & $0.3850,0.4525$ & $0.3957,0.4429$ \\
\hline
\end{tabular}

MAM $_{\text {index }}$ : Mitral annulus motion indexed to body surface area; LAFS: Long-axis fractional shortening; SD: Standard deviation; CI: Confidence interval.

A moderate positive correlation was found to exist between the left-ventricular end-diastolic diameter and either MAM $_{\text {index }}$ or LAFS (Figure 3), as well as a strong positive $(\mathrm{R}=0.7309, \mathrm{P}=0.0030)$ correlation between MAM $_{\text {index }}$ and LAFS (Figure 4). The remainder of the echocardiographic parameters, body weight and heart rate did not correlate significantly with either LAFS or the indexed MAM (Table 2).

Finally, when the reproducibility of these indices was investigated, strong inter-observer and intra-observer agreements were calculated for both MAM $_{\text {index }}$ and LAFS (Table 3). 
Figure 3. Scatterplots showing the moderate correlations between the left-ventricular internal diameter in diastole $\left(\mathrm{LV}_{\mathrm{d}}\right)$ and both long-axis fractional shortening $(\mathrm{A})$ and the mitral annulus motion indexed to body surface area $(\mathrm{B})$. Best-fit lines and linear regression equations are shown.
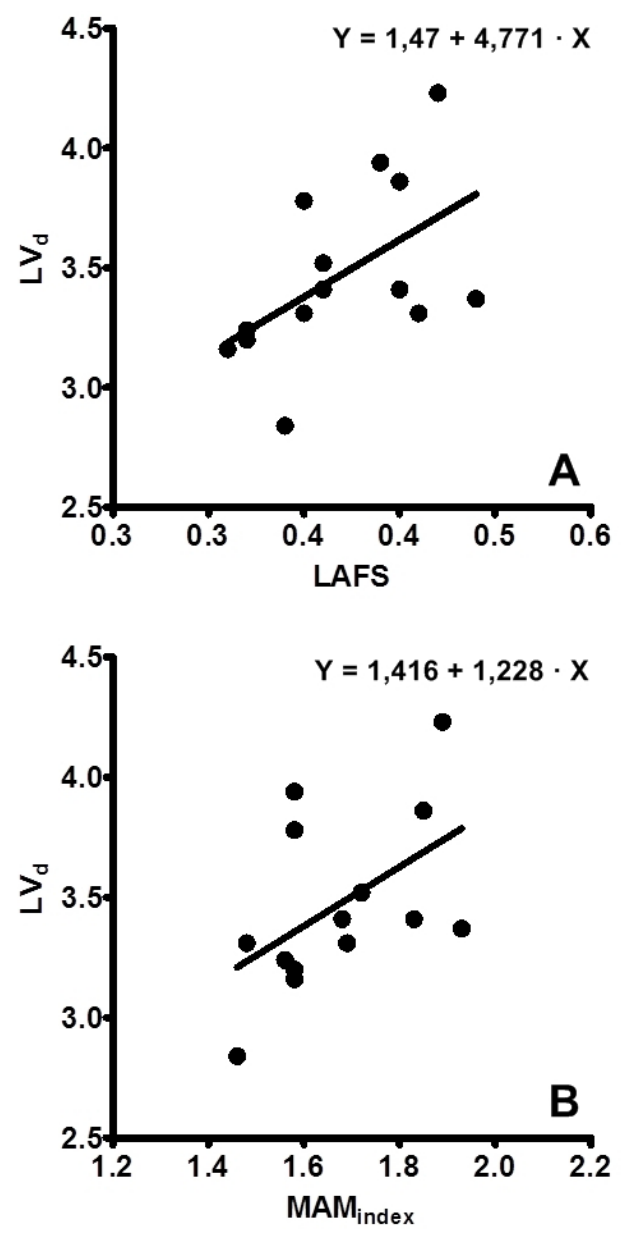

Figure 4. Scatterplot indicating a strong correlation between the long-axis fractional shortening and the mitral annulus motion indexed to body surface area. The best-fit line and linear regression equation are shown.

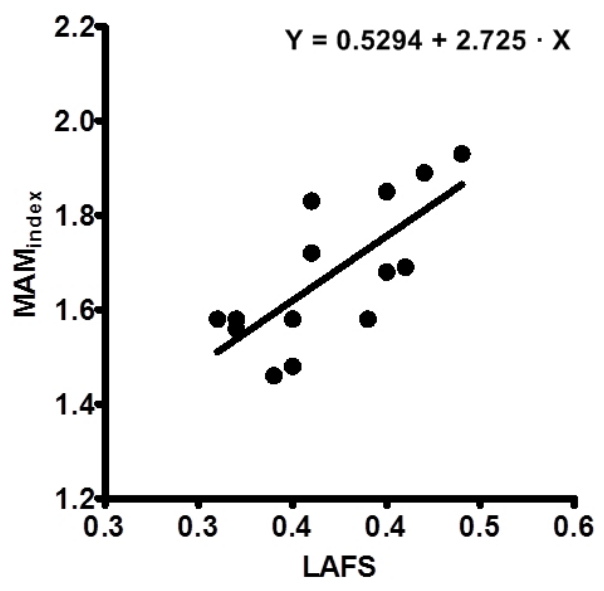


Table 2. Correlation of several parameters with the long-axis fractional shortening and the indexed mitral annulus motion in dogs.

\begin{tabular}{lcccccc}
\hline \multirow{2}{*}{ Parameters } & \multicolumn{3}{c}{ LAFS } & \multicolumn{3}{c}{ MAM $_{\text {index }}$} \\
\cline { 2 - 7 } & $\mathbf{R}$ & $\mathbf{9 5 \%} \mathbf{C I}$ & $\boldsymbol{P}$ & $\mathbf{R}$ & $\mathbf{9 5 \%} \mathbf{C I}$ & $\boldsymbol{P}$ \\
\hline BW & -0.0952 & $-0.5958,0.4586$ & 0.3730 & 0.1874 & $-0.3812,0.6531$ & 0.2609 \\
$\mathrm{HR}$ & 0.1397 & $-0.4223,0.6241$ & 0.3169 & 0.0744 & $-0.4750,0.5821$ & 0.4002 \\
$\mathrm{FS}$ & 0.2048 & $-0.3656,0.6634$ & 0.2412 & 0.0824 & $-0.4687,0.5875$ & 0.3896 \\
$\mathrm{EF}$ & 0.2767 & $-0.2977,0.7040$ & 0.1691 & 0.1933 & $-0.3759,0.6566$ & 0.2539 \\
LV $_{\mathrm{s}}$ & 0.3484 & $-0.2236,0.7419$ & 0.1111 & 0.4155 & $-0.1478,0.7752$ & 0.0698 \\
LV $_{\mathrm{d}}$ & 0.5333 & $0.0036,0.8293$ & 0.0248 & 0.5119 & $-0.0257,0.8199$ & 0.0306 \\
LA/Ao & 0.1585 & $-0.4064,0.6357$ & 0.2942 & 0.2524 & $-0.3213,0.6906$ & 0.1920 \\
\hline
\end{tabular}

$\mathrm{MAM}_{\text {index }}$ : Mitral annulus motion indexed to body surface area; LAFS: long-axis fractional shortening; HR: Heart rate; FS: Fractional shortening; EF: Ejection fraction; $\mathrm{LV}_{\mathrm{s}}$ : Left-ventricular end-systolic diameter; $\mathrm{LV}_{\mathrm{d}}$ : Left-ventricular end-diastolic diameter; LA/Ao: Left atrium-to-aorta ratio; BW: Body weight; CI: Confidence interval.

Table 3. The intra and interobserver reproducibility of mitral annulus motion and the long-axis shortening fraction in dogs.

\begin{tabular}{lcc}
\hline \multicolumn{1}{c}{ Parameter } & Intra-observer agreement & Inter-observer agreement \\
\hline $\mathrm{MAM}_{\text {index }}$ & $\mathrm{R}=0.8284, \mathrm{P}=0.0003$ & $\mathrm{R}=0.7444, \mathrm{P}=0.0023$ \\
$\mathrm{LAFS}$ & $\mathrm{R}=0.8284, \mathrm{P}=0.0003$ & $\mathrm{R}=0.7709, \mathrm{P}=0.0006$ \\
\hline
\end{tabular}

$\mathrm{MAM}_{\text {index }}$ : Mitral annulus motion indexed to body surface area; LAFS: long-axis fractional shortening.

\section{Discussion}

The longitudinal myocardial fibers, which are located within the subepicardial and subendocardial heart layers, are known to play an important role in ventricular function. Their contraction leads to a longitudinal shortening of the left ventricle, therefore displacing the mitral annulus toward the heart apex (JONES et al., 1990). According to Emilsson et al. (2001), longitudinal shortening represents the main component of cardiac pumping function. Therefore, it seems reasonable that variables targeted at both circumferential and longitudinal shortening should be included in the echocardiogram for the comprehensive evaluation of left ventricular systolic function and the early recognition of contractile abnormalities.

Mitral annulus motion is able to provide tridimensional information regarding left ventricular contraction, regardless of its geometry (ALAM,
1991). Pai et al. (1991) mentioned that MAM reflects the movement of the mitral annulus in relation to the transducer, although it may not be considered as a measurement of longitudinal fractional shortening. To overcome this limitation, we compared MAM with LAFS, which is regarded as a more reliable estimate of systolic function, since it considers the ventricular length as well. In a study that included 30 healthy people, a strong linear correlation was documented between MAM and LAFS (EMILSSON et al., 2006), which is similar to the results presented herein. In people with myocardial hypertrophy, the impairment of longitudinal contractile function was demonstrated prematurely as compared to the radial function. Since the latter is assessed using both the ejection fraction and fractional shortening, this parameter may still be normal at the very beginning of myocardial compromise, while MAM could potentially be used as a marker of early systolic dysfunction (HU et al., 2013). 
When assessed altogether, the longitudinal and radial shortenings increase the reliability of the functional myocardial evaluation by excluding the possibility of a reduced contractility in one axis being offset by augmented function in the other, as might be documented if either nonuniform myocardial contractile function or alterations in fiber orientation are present, such as in some cardiac diseases (AURIGEMMA, 1995; SCHOBER; FUENTES, 2001). Interestingly, Schober and Fuentes (2001) reported that an animal with dilated cardiomyopathy and radial fractional shortening of $0 \%$ may still exhibit a fairly preserved systolic function when it is examined as the long-axis fractional shortening. Also, in human beings with heart failure and a preserved ejection fraction, left ventricular circumferential dysfunction was documented prior to longitudinal impairment (CIOFFI et al., 2012). It is worth mentioning, however, that the long-axis fractional shortening that we compared to MAM in this investigation is not the same as the radial fractional shortening calculated using long-axis images. Although the calculation of the fractional shortening using M-mode and long-axis images results in slightly lower values than those obtained using short-axis views in either healthy or diseased dogs, they are considered equivalent measures (SCHOBER; BAADE, 2000) and therefore are dependent on the radial displacement of both the interventricular septum and left ventricular free wall.

As hypothesized, MAM and LAFS were not correlated with the ejection fraction, although weak-to-moderate linear correlations with such parameters have been demonstrated previously (ALAM, 1991; EMILSSON et al., 2006). The same was observed for the radial fractional shortening, which had no relationship with MAM, contrasting with a preceding investigation that found a weak correlation with the body weightindexed MAM in normal dogs as well as in dogs with cardiac disease, even though a correlation could not be demonstrated when the non-indexed MAM was used (SCHOBER; FUENTES, 2001).
The inverse relationship between left ventricular long- and short-axis dynamics anticipated from previous studies in dogs with heart dysfunction can explain this curious finding. Therefore, it is paramount that the relationship between short- and long-axis contractions be understood so that overt contradictory echocardiographic findings can be explained in a clinical setting (SHANNON et al., 1991; SUZUKI et al., 1997).

In this study, we did not find any significant differences for MAM and LAFS between healthy dogs and those with mitral valve insufficiency. The results of the indexed MAM pointed to a $95 \%$ confidence interval ranging from 1.58 to $1.76 \mathrm{~cm}$ $\mathrm{m}^{-2}$, which falls into the 1.47 to $1.83 \mathrm{~cm} \mathrm{~m}^{-2}$ range proposed by Schoberand Fuentes (2001) for similarly sized dogs. For dogs with mitral valve disease, the same investigation found a median indexed MAM of $1.6 \mathrm{~cm} \mathrm{~m}^{-2}$, although the range was much wider (0.89 to 6.3). In our study all dogs with incompetent mitral valves were classified as ACVIM stage B2, which means an absence of clinical signs despite the identification of some cardiac remodeling. In this setting, the MAM documented for these animals was within the normal range as well, and no difference was attained when compared to the healthy subjects. Other cardiac diseases with a more exaggerated systolic component have resulted in a diminished MAM, including acute myocardial infarction in human beings (ALAM, 1991) and dilated cardiomyopathy in both dogs (SCHOBER; FUENTES, 2001) and people (PAI et al., 1991).

Although not significant, the values of MAM and LAFS were lower in the dogs with acquired mitral valve degeneration recruited for this study, contrasting with former results that demonstrated a significantly higher indexed MAM for the animals with mitral insufficiency in comparison with the healthy animals (SCHOBER; FUENTES, 2001). As mentioned before, however, we only studied ACVIM B2 dogs in which myocardial remodeling was minimal (ATKINS et al., 2009), as supported by a mean increase of 1.73 in the left atrium-to- 
aorta ratio. From another perspective, some dogs in congestive heart failure and severely altered loading conditions are likely to exhibit augmented MAM, similar to what was found by Schober and Fuentes (2001), in spite of their preserved systolic function. Because of the volume overload that accompanies congestive heart failure, the stretched muscular fibers are supposed to react vigorously in response to altered mechanical properties which results in increased inotropy, thereby augmenting MAM as well. On the other hand, in a scenario of advanced heart failure, the compromised systolic function may interfere with such a response (WANG et al., 2013), which in turn can reduce MAM.

Because the diastolic diameter of the left ventricle is a surrogate for preload, the significant correlations found between both MAM and LAFS and $\mathrm{LV}_{\mathrm{d}}$ are supportive of the volume dependency of these two parameters. Again, this finding may be ascribed to the length-tension relationship of the myocardium, which is simplistically explained by the Frank-Starling law, i.e., volume overload causes myocyte stretching and increases sarcomere length, leading to augmented force generation (WANG et al., 2013).

Contrasting with the results of a prior study that reported a weak and strong linear relationship with HR and body weight, respectively (SCHOBER; FUENTES, 2001), we did not find a correlation between the apex displacement of the mitral annulus and either heart rate or body weight. These findings might be attributable to our population consisting of a single breed with no prominent disparities in body weight, as opposed to the studies by Schober and Fuentes (2001), in which several breeds were represented and the dogs ranged from 2 to $75 \mathrm{~kg}$. Also, because the dogs belonged to the university kennel, they were used to manipulation, precluding marked fluctuations in heart rate.

One of the most positive outcomes of this investigation is the possibility of calculating MAM and LAFS using any ultrasound machine. Also, these parameters represent reliable indicators of the functional status of the longitudinal myocardial fibers, which are normally not assessed during the routine exam. However, several limitations also exist, and include the reduced number of dogs enrolled, which impeded the classification of both MAM and LAFS using breed and body weight criteria. For the dogs with mitral valve disease, the absence of animals with advanced congestive heart failure precluded the investigation of the sensitivity and specificity of these parameters to identify systolic dysfunction as compared to the echocardiographic variables routinely utilized to do so. Additional studies may clarify if these indices can bring any benefit to the regular echocardiographic evaluation in dogs with altered cardiac function.

\section{Conclusion}

In conclusion, besides being easily calculated, MAM and LAFS performed independently of gender, HR, LA/Ao, competency of the mitral valve and afterload. The correlation found between LAFS and LV end-diastolic dimension supports its dependency on preload.

\section{Acknowledgements}

The authors would like to thank Conselho Nacional de Desenvolvimento Científico e Tecnológico (CNPq) for the financial support of this study.

\section{References}

ALAM, M. The atrioventricular plane displacement as a means of evaluating left ventricular systolic function in acute myocardial infarction. Clinical Cardiology, Hoboken, v. 14, n. 7, p. 588-594, 1991.

ATKINS, C.; BONAGURA, S.; ETTINGER, S.; FOX, P.; GORDON, S.; HAGGSTROM, J.; HAMLIN, R.; KEENE, B.; FUENTES, L.; STEPIEN, R. Guidelines for the diagnosis and treatment of canine chronic valvular heart disease. Journal of Veterinary Internal Medicine, Philadelphia, v. 23, n. 6, p. 1142-1140, 2009. 
ATKINS, C. E.; CURTIS, M. B.; MCGUIRK, S. M.; KITTLESON, M. D.; SATO, T.; SNYDER, S. The use of M-mode echocardiography in determining cardiac output in dogs with normal, low, and high output states: comparison to thermodilution method. Veterinary Radiology \& Ultrasound, Raleigh, v. 33, n. 5, p. 297-304, 1992.

AURIGEMMA, G. P.; SILVER, K. H.; PRIEST, M. A.; GAASCH, M. D. Geometric changes allow normal ejection fraction despite depressed myocardial shortening in hypertensive left ventricular hypertrophy. Journal of American College of Cardiology, New York, v. 26, n. 1, p. 195-202, 1995.

CIOFFI, G.; SENNI, M.; TARANTINI, L.; FAGGIANO, P.; ROSSI, A.; STEFENELLI, C.; RUSSO, T. E.; ALESSANDRO, S.; FURLANELLO, F.; SIMONE, G. Analysis of circumferential and longitudinal left ventricular systolic function in patients with non-ischemic chronic heart failure and preserved ejection fraction. The American Journal of Cardiology, New York, v. 109, n. 3, p. 383-389, 2012.

EMILSSON, K.; BRUDIN, L.; WANDT, B. The mode of left ventricular pumping: is there an outer contour change in addition to the atrioventricular plane displacement? Clinical Physiology, Oxford, v. 21, n. 4, p. 437-446, 2001.

EMILSSON, K.; EGERLID, R.; NYGREN, B. M.; WANDT, B. Mitral annulus motion versus longaxis fractional shortening. Experimental \& Clinical Cardiology, Bern, v. 11, n. 4, p. 302-304, 2006.

HU, K.; LIU, D.; HERRMANN, S.; NIEMANN, M.; GAUDRON, P. D.; VOELKER, W.; ERTL, G.; BIJNENS, B.; WEIDEMANN, F. Clinical implication of mitral annular plane systolic excursion for patients with cardiovascular disease. European Heart Journal, Oxford, v. 14, n. 3, p. 205-2012, 2013.
JONES, C. J. H.; RAPOSO, L.; GIBSON, D. G. Functional importance of the long axis dynamics of the human left ventricle. British Heart Journal, London, v. 63, n. 4, p. 215-220, 1990.

PAI, R. G.; BODENHEIMER, M. M.; PAI, M. S.; KOSS, J. H.; ADAMICK, R. D. Usefulness of systolic excursion of the mitral annulus as an index of left ventricular systolic function. The American Journal of Cardiology, New York, v. 67, n. 2, p. 222-224, 1991.

SCHOBER, K. E.; BAADE, H. Comparability of left ventricular M-Mode Echocardiography in dogs performed in long-axis and short-axis. Veterinary Radiology \& Ultrasound, Raleigh, v. 41, n. 6, p. 543-549, 2000.

SCHOBER, K. E.; FUENTES, V. L. Mitral Annulus motion as determined by M-Mode echocardiography in normal dogs and dogs with cardiac disease. Veterinary Radiology \& Ultrasound, Raleigh, v. 42, n. 1, p. 52-61, 2001.

SHANNON, R. P.; KOMAMURA, K.; STAMBLER, B. S.; BIGAUD, M.; MANDERS, W. T.; VATNER, S. F. Alterations in myocardial contractility in conscious dogs with dilated cardiomyopathy. American Journal of Physiology, Bethesda, v. 260, n. 6, p. H1903-H1911, 1991.

SUZUKI, M.; CHENG, C. P.; OHTE, N.; LITTLE, W. C. Left ventricular spherical dilation and regional contractile dysfunction in dogs with heart failure. American Journal of Physiology, Bethesda, v. 273, n. 3, p. H1058-H1067, 1997.

WANG, L.; ISAACS, S. K.; WEINER, M. S.; WEYMAN, A. E.; PICARD, M. H.; BAGGISH, A. L.; WEINER, R. B. The impact of normal saline infusion on myocardial deformation: mechanistic insight into the frank-starling law. Circulation, Boston, v. 128, n. 22, p. A15168, 2013. 